\title{
LOS MORISCOS Y LA JUSTICIA. NOTAS SOBRE LA PRÁCTICA PROCESAL EN LA CORT DE VALLDIGNA
}

\author{
EUGENIO CÍSCAR PALLARÉS
}

Fecha de recepción: noviembre 2008

Fecha de aceptación marzo 2009

Uno de los aspectos poco estudiados de los moriscos es su relación y comportamiento ante determinadas instituciones, así como las particularidades que su propia especificidad plantearon a lo largo del tiempo, tanto en ámbitos reales como señoriales (competencias, acceso, tramitación, trato recibido, soluciones adoptadas...). Una de esas instituciones es la administración de Justicia, de la Justicia ordinaria y común, la que resolvía la generalidad de asuntos civiles o criminales del conjunto de la población en su vida cotidiana.

En ese sentido queremos aquí traer a colación algunas observaciones y reflexiones derivadas de la práctica procesal en la cort de Valldigna, zona ampliamente poblada por moriscos, junto con una destacada minoría cristiana, de la que se ha conservado una abundante documentación procesal ${ }^{1}$.

Con carácter previo e introductorio, habría que preguntarse primeramente por la efectividad de la «tolerancia» legal de la época mudéjar. Es bien sabido que, a raíz del proceso de Reconquista en el siglo XIII, los musulmanes que no huyeron y optaron por quedarse en sus mismos territorios, o en otros bajo dominio cristiano, fueron respetados en sus creencias religiosas, en su lengua, costumbres... y en su propia normativa jurídica, recogida en la Sunna y Xara. Al parecer, esta permisividad se mantuvo en líneas generales, salvo en momentos de radicalismo y exacerbación. Pero, podemos plantearnos si hubo realmente esa pretendida rígida separación y estricta tolerancia legal, con carácter general; si las autoridades reales se abstuvieron sistemáticamente de

1. Este trabajo remite necesariamente a una obra general sobre dicha cort durante la Edad Moderna, en vías de publicación y con el título de La Justicia del Abad. Justicia Señorial y Sociedad en el Reino de Valencia (Valldigna, siglos XVI, XVII y XVIII). No obstante, aparte del contexto general y las principales conclusiones, aquí profundizamos en algunas materias y desarrollamos en detalle otras, con referencia siempre a la amplia base procesal de dicha institución judicial. 
conocer los pleitos civiles o de intervenir en las causas criminales de mudéjares; si la justicia señorial, en un momento de fortalecimiento de la autoridad baronal, se desentendió de la aplicación de la Justicia sobre esta población, y por tanto, en dejación de la manifestación más evidente de su poder sobre los vasallos. $\mathrm{O}$, en su caso, de todos los matices, contradicciones, situaciones ambiguas que, a lo largo del tiempo, se fueron suscitando en esta materia.

No parece que este tema haya atraído mucho la atención de los medievalistas. J. Boswell indica que, para mediados del siglo XIV, hubo muchas injerencias cristianas para resolver cuestiones de musulmanes. Puede ser que ello se viera favorecido por la situación de inestabilidad provocada por la guerra entre Castilla y Aragón (13551366), como puntualiza M. D. Meyerson. Para este último autor, sin embargo, con carácter general los cadís (el cadí general y los cadís menores) resolvían los casos entre musulmanes y los asuntos mixtos eran conocidos por tribunales cristianos, sin haber observado interferencias o intromisiones cristianas de trascendencia en tiempos de Fernando II El Católico; para esta época, los jueces cristianos y musulmanes habían llegado a un «modus vivendi» jurídico, en que unos y otros respetaban sus propias esferas exclusivas y al mismo tiempo eran capaces de cooperar en aquellos supuestos en que coincidían los dos sistemas legales ${ }^{2}$. De todos modos, el mismo Meyerson pone de relieve la complejidad de la materia y sus muchos claroscuros ${ }^{3}$.

En la Valldigna, la población originaria fue casi exclusivamente musulmana en el siglo XIII, y solo poco después atrajo unos repobladores cristianos en la localidad del Rafol y en las cercanías del monasterio en Simat. Un privilegio de 1298 permitía a los sarracenos regirse por su ley y Zuna, continuar con su sistema económico, religión, derecho civil, nombramiento de cargos (alamín, alcadí...) $)^{4}$. No obstante, la Justicia en el señorío se regía por un Justicia Mayor, que actuaba en nombre del Abad, de cuyo cargo hay constancia desde principios del siglo XIV, y sin duda desconocía las normas jurídicas de origen islámico. No sabemos hasta qué punto en el siglo XIV y principios del XV coexistieron para la población mudéjar un juez «cristiano» con un juez musulmán (o «cadí») para distintas cuestiones, con notarios especializados, como los alfaquíes. Es probable que esta simultaneidad de derechos, en ausencia de una delimitación

2. Meyerson, M. D.: Els musulmans de Valencia en l'época de Ferran i Isabel, Valencia, Ed.. Alfons el Magnánim, Generalitat Valenciana, 1994, p. 327 y ss. No obstante, hay que advertir que los estudios y fuentes de Meyerson se centran, ante todo, en las ciudades reales y la documentación de la corona, cuando los mudéjares vivían ante todo en lugares de señorío.

3. Ibídem. Había delitos»hadd», recogidos en textos religiosos musulmanes, que solo juzgaba el cadí (sexo prematrimonial, adulterio, acusaciones calumniosas de fornicación, robos, beber vino...) y otros no estaban claramente regulados y los juzgaba la policía u otro gobernante musulmán. El cadi juzgaba y los funcionarios reales ejecutaban la sentencia. A veces, los mismos mudéjares planteaban sus asuntos ante los tribunales cristianos. No dejaron de producirse conflictos jurisdiccionales (vg., entre el bayle y el gobernador, entre los bayles y las justicias locales, entre los señores de vasallos y las autoridades reales..), etc.

4. Citado por Gascon Pelegrí, V., Historia de Tabernes de Valldigna, Valencia, 1965, reeditado en 1981, pp. 63-64. 
clara, planteara problemas de roce o conflicto entre qué norma aplicar o por qué juez, en algún caso determinado.

Esa situación es la que parecen indicar algunos capítulos de la sentencia arbitral de $1457^{5}$, en respuesta a escritos de queja anteriores o indicaciones originarias, que no conocemos expresa o literalmente. Así, el capítulo 29 de la misma establece (en respuesta al llamado «capitol xxxiii», desconocido) que el Abad y sus oficiales, «en los casos que deu servar Zuna e Xara, sien tenguts servar Zuna e Xara al dits moros e vasalls, en los casos que deu jutgar per Furs y Privilegis que jutge segons ells». En el capítulo 48 de la citada sentencia arbitral se afirma que (en relación al desconocido «capitol xxi» de los escritos de queja o petición) «declaram ut supra sia feta Justicia segons Zuna e Xara».

Estos capítulos citados están evidenciando la aplicación simultánea de dos derechos, el cristiano de los Fueros y el musulmán de la Suna y Xara; que hubo conflictos de jurisdicción en algunos casos, que había supuestos de deslinde nada claro, o posible aplicación intencionada o negligente de un derecho inadecuado, etc.. Este sistema de dualidad legal ocasionó alteraciones o discordancias que, a juicio de los vasallos, el Abad y sus oficiales no respetaban siempre que debían las normas de derecho musulmán, quizá no absteniéndose en determinadas circunstancias ante los jueces mudéjares.

De igual manera, las referencias citadas ponen de relieve el intento renovado de volver a una situación tradicional, que mantuviese la convivencia entre estos dos cuerpos legislativos, sin que podamos precisar en qué materias o casos se aplicaba una u otra legislación. Ni tampoco, si se cumplió en todo o parte, si se llevó a la práctica o no.

Así, de hecho, los Libros de Justicia de la cort conservados de fines del siglo XV y principios del siglo XVI, gestionados o dirigidos por los respectivos Justicias Mayores, admiten reclamaciones de cantidad y algunas cuestiones civiles normales por parte de mudéjares y aplican el derecho, según normas procesales al uso, sin diferenciar o indicar qué normativa aplican, o sin que, en su caso, hubiese diferencia entre ellos ${ }^{6}$. De igual manera hemos localizado algunos pocos procesos penales de musulmanes en documentación independiente, en donde parece perseguirse las infracciones criminales como si fueran de cristianos, sin ninguna particularidad ${ }^{7}$. No parece, pues, que en esta época tardía la diferenciación legal entre una y otra población, o entre uno y otro derecho, fuese muy tajante o rígida. Es posible, como mera hipótesis, que se abriese

5. Importante y larga sentencia arbitral, dictada en 1457 por Joan de Mompalau y Mahomat Ripoll, con el objetivo de poner fin y resolver las muchas cuestiones discutidas en el régimen señorial de la Valldigna entre el Abad y convento y sus vasallos, tanto mudéjares como cristianos. Puede encontrarse en Archivo del Reino de Valencia (ARV): Clero (Cl), libro 2.440, y en el mismo archivo, Justicia Civil, $\mathrm{n}^{\mathrm{o}} 1.181$ (antes 1.182), año 1570 , mano 61.

6. Aunque no hemos estudiado exhaustivamente esa documentación, así se observa, por ejemplo, en el Libro de la Justicia de 1515-1516, ARV: Cl., caja (c.) 1.949-50.

7. Hemos encontrado más de quince procesos penales, en expedientes independientes, contra mudéjares de los pueblos de Valldigna, anteriores a 1525. 
un abanico flexible de posibilidades, de libre opción..., en donde las particularidades mudéjares tuviesen cabida, pero en franco retroceso ante el predominio cada vez mayor de un mundo cristiano regido por los Fueros.

Fuesen cuales fuesen las distinciones entre ambos cuerpos jurídicos y su posible aplicación simultánea, más o menos parcial, o circunscrita a cuestiones muy especificas del mundo musulmán, lo cierto es que con la conversión forzosa de 1525, esas diferencias dejaron de tener sentido, de apreciarse o de considerarse. El Libro de la Justicia de 1526 es sintomático porque, como los anteriores, no hace alusión a la aplicación de uno u otro Derecho, siendo todas las referencias legales, en su caso, remitidas a los Fueros. Sin embargo, puntualmente afloran algunas peculiaridades mudéjares en algún tema, que se arrastran del pasado; por ejemplo, en las dotes o «acidachs» mudéjares, sus requisitos de constitución y las particularidades de su cancelación y devolución.

En 30 de enero de 1526, comparece ante el prior Gaspar Bellver el procurador de María (¿Obaydal?), viuda del alfaquí Ali Cabanet (o Sabanet), y manifiesta que es acreedora «per raho de son accidats» de determinadas propiedades y cantidades contra los bienes de su difunto marido, los cuales están siendo objeto de pública subasta por «les culpes y delictes de son marit» y que ella no debe sufrir las consecuencias, solicitando que se le devuelvan sus bienes y dote. Varios testigos moriscos afirman que la viuda procede de Alfulell, que es de una familia principal, que recibió varias propiedades de su padre cuando murió, que no sabían si había hecho «accidats», pero lo tienen por cierto, "perque totes les mores quant se casen los fan accidats»; "Que segons us e practica que solien tenyr los moros observada de gran temps en sa y segons dret de Çuna Xara totes les mores quant se casaven feyen cartes de accidats ab los marits y nos podra casar ni dir muller verdadera dona alguna sens que noy hagues cartes de accidats en les quals se posava la donatio o dot que los marits feyen a les mullers». La «carta de accidats» se había perdido cuando los agermanados entraron a robar en el valle, pero que, según Çuna Xara y practica entre moros, cuando se perdía, se pagaba la dote según decía la mujer o se justipreciaba, «y es la raho per que les dones necessariament quant se casen han de tenyr accidats y perque entre los moros nos acostuma tenyr prothocols ny registres dels dits accidats». Al día siguiente se pone de relieve que era el alcadí (sic) el que anteriormente «rebia cartes de accidats y jutgava entre los moros», que cuando se casaba una mora y era «honrada» se le hacía un «accidats» de 130 a 150 libras y no menos, y que cuando se perdía el «accidats» se le pagaba como a su hermana o pariente, y en su defecto, el de una mujer «consemblant», etc. Tras la práctica de dicha prueba testifical, además de pericial de derecho musulmán, el prior dicta sentencia el 31 de enero («incontinenti»), asesorado por el doctor Frances Vives, estimando la demanda y afirmando que «Segons Çuna y Xara, practica y usança observada en la present vall en lo temps que eren moros, quant alguna dona casada perdia lo accidats o nos provava haber accidats se li havya de pagar aquell 
segons accidats de altra parenta sua o de altra dona consemblant», ordenando que se proceda de igual manera ${ }^{8}$.

En fin, se trata de los últimos vestigios de una simultaneidad legal bajomedieval, que se había roto definitivamente con la conversión forzosa de 1525, al menos en términos «oficiales», mas allá de las prácticas y costumbres mantenidas en el ámbito privado y que no llegarían a plantearse ante los tribunales de Justicia. En ese sentido, en el ámbito del Derecho al menos, se había resuelto una antigua dualidad, quizá con límites imprecisos, que arrancaba de la época de la Reconquista.

Sin duda, el proceso de acomodación a las nuevas estructuras legales debió de ser lento y progresivo. Pasados los años, la fuerte raigambre de la cultura musulmana y la lengua árabe («algarabia») entre la comunidad morisca del valle permitía aún a los antiguos alfaquíes ${ }^{9}$ seguir ejerciendo y trabajando, al menos en ámbitos estrictamente jurídicos. Así, a mediados de los años cincuenta del siglo XVI se planteó un agudo problema de partición de herencia en la pudiente familia morisca Zignell de Tavernes. En 1558 se suscitó por ese motivo un pleito entre Frances o Çat Zignell por un lado y su madre la viuda Zignell y los otros hijos o hermanos por otro. De este proceso se desprende que las partes habían llegado, hacía 15 o 16 meses, a un acuerdo (o «concordia»), que luego anularon y renovaron por otro distinto, habiendo pedido en ambos casos a Joan Talaya, olim alfaquí Talaya, morisco de Benifairó de Valldigna, «ques fesen scrits de ma del dit testimoni (Talaya) en lengua morisca elegida aquella e ben entesa»; firmaron las partes y luego se tradujo «per tercera persona e interprete en lengua valenciana» y recogida por el notario del valle Frances Garcia. Pero en ese momento, las partes discreparon sobre lo escrito en dicha segunda «concordia» o convenio, traducida al valenciano, y se negó que reflejase realmente lo acordado anteriormente $^{10}$. Con todo, la documentación notarial conservada desde mediados del Quinientos permite comprobar que los moriscos acudían ya con cierta normalidad, o con bastante asiduidad, a estos profesionales, los notarios cristianos (vg. protocolos de Nofre Joan Roures: «procuras», ventas, «apocas», «debitoris», donaciones... $)^{11}$.

8. Se hace constar a continuación en el proceso, que se busca un «accidats» semejante, tomando como referencia el de una hija de la viuda demandante. Fue otorgado ante el alfaquí Abdala Zomila de Tavernes en 1525; Moscaire, morisco de Gandía, juró leerlo e interpretarlo bien; tras sumar los diversos conceptos (besantes, doblas de oro, dinero para «vestits», media casa...) se evalúa globalmente la dote en 106 L. 13 s. 4 d. (Vid. Libro de Justicia de1526, sin foliar, anotación de 30 de enero de 1526, ARV: Cl., c. 2.20708). Para un resumen general de dicho libro, vid. La Justicia del Abad (en prensa), referida en nota 1.

9. En el Libro de Justicia citado en la nota anterior, se mencionan cuatro alfaquíes al menos: Abdalá Zomila, de Tavernes; Alí Sabanet, de Alfulell; Azmet Negral, estos dos últimos fallecidos ya en 1526, más referencia a un alfaquí en la Hombría.

10. ARV: Cl. c. 1.905, proces de Frances Zignell als Cappatrut, morisco de Taverna, contra Catherina Zignell, viuda, y altres fills de ella, iniciado el 20 de abril de 1558. En este caso, carece de interés el contenido de la discrepancia; al parecer, el actor negaba que se hubiese comprometido a ayudar a sus hermanas en sus bodas, pagando el primer año 60 doblas de oro y 20 el segundo, etc..

11. Vid epígrafe «Aproximación a la práctica notarial», en La Justicia del Abad (en prensa). 
Otra cuestión es la eficacia de la protección que la Bailía o el Bayle General de la Ciudad y Reino de Valencia otorgaba a los mudéjares. El conocimiento del funcionamiento de esta institución, sobre todo en el complejo abanico de sus competencias, está lejos de ser satisfactorio, tanto en la Baja Edad Media como en la época foral moderna $^{12}$. Una de sus misiones era la de velar por los intereses de las minorías religiosas (especialmente, judíos y mudéjares), protegiendo sus privilegios y libertades y acogiendo judicialmente sus demandas y peticiones. Tal particularidad pudo tener su desarrollo natural en los territorios de jurisdicción real o realengo, pero cabe preguntarse cómo se tradujo o en qué se plasmó, en su caso, en los ámbitos de señorío. La población mudéjar residía mayoritariamente en zonas de jurisdicción señorial, la cual se esforzaba en aumentar sus competencias y autonomía, especialmente ya en el siglo XV. Por tanto, la posibilidad de los vasallos mudéjares de plantear sus disquisiciones con los señores ante el Bayle General encajaba mal o no se conciliaba judicialmente con las pretensiones de la jurisdicción señorial. Se debieron plantear conflictos de jurisdicción, entre la plena competencia de los señores sobre sus vasallos y el privilegio de las minorías religiosas de acudir al citado tribunal real ${ }^{13}$.

Sin embargo, y siempre en teoría, tal contradicción dejaba de tener sentido con la expulsión o conversión forzosa de los judíos (1492) y de los mudéjares (1525); en esas circunstancias quedaba vacía de contenido la protección de unas minorías religiosas, que en principio habían desaparecido, al menos legalmente.

En lo que hace referencia a la Valldigna, era lógico que los mudéjares acudieran a la Bailía en búsqueda de protección legal o judicial, pero de hecho apenas conocemos ejemplos de esa opción. Un gran conflicto entre el convento y los vasallos, tanto moros como cristianos, se resolvió por medio de una sentencia arbitral en 1457, sin que nos conste documentalmente que dichas discrepancias se hubiesen planteado previamente ante un tribunal real, distinto a la jurisdicción del Abad. En cambio, para unos años más tarde (1480-1482), M. Meyerson pone de relieve el enfrentamiento entre el cardenal de Valencia y señor de Valldigna y el Bayle General. Los vasallos de esta zona tenían la costumbre de apelar ante el Bayle General las decisiones del Justicia de Valldigna;

12. PILES Ros, L:, Estudio documental sobre el bayle general de Valencia, su autoridad y jurisdicción, Valencia: Institución Alfonso el Magnánimo, 1970; GrAullera SANZ, V.: Historia del Derecho Foral Valenciano, Valencia: Tyris, 1994, pp. 56-57; SALVADOR ESTEBAN, E.: «La frontera intrarregnícola valenciana y su impacto en las instituciones reales. El ejemplo de las Bailías Generales», Pedralbes, Barcelona, 1993, n 13-II, pp. 11-23; IBORRA LERMA, J. M.: Realengo y Señorío en el Camp de Morvedre, Sagunto: Confederación Española de Cajas de Ahorro, 1981, pp. 195-204.

13. PÉrez GARCíA, P., El Justicia Criminal de Valencia (1479-1707): Una magistratura urbana valenciana ante la consolidación del absolutismo, Valencia: Generalitat Valenciana, 1991, pp. 45-47 y 78-79. Puntualiza este autor que, dadas las amplias y variadas competencias de la Bailía, eran frecuentes los conflictos de jurisdicción con otros tribunales, entre ellos el Justicia de Valencia, así como que la expulsión de los judíos (1492) y la conversión forzosa de los mudéjares valencianos (1525) «redujo considerablemente la conflictividad jurisdiccional entre ambos tribunales» (Baylía y «consell» de Valencia) (p. 79). También M. MEYERSON alude a conflictos generales entre la jurisdicción señorial y diversos tribunales reales, entre ellos la Baylia, en temas de mudéjares (Op. cit, pp. 362 y ss.). 
lo hacían tan frecuentemente que el rey había designado un asesor especial para que le asistiese en la resolución de estas causas. Si bien en principio esto parecía legal, se hacía con tanta frecuencia que parecía convertirse en un tribunal de primera instancia; hasta tal punto se abusaba de este posibilidad, que el monarca Fernando II tuvo que indicarle al Bayle que se inmiscuyera lo menos posible ${ }^{14}$. Incluso hubo alguna actuación de abierta resistencia o menosprecio ${ }^{15}$.

En 1501 también acudieron los pueblos del valle ante este tribunal real en protesta por determinadas restricciones señoriales en la utilización y partición de las algarrobas o en la regulación de los «acidachs» o dotes de las mujeres al contraer matrimonio, sin que nos conste el resultado. En los años veinte del siglo XVI se solicita licencia al Bayle para endeudarse («carregarse» de censales) (y otras semejantes a la Gobernación) ${ }^{16}$.

No obstante, es lógico pensar que desde la conversión forzosa de 1525, al ser los cristianos nuevos o moriscos jurídicamente «iguales» a los cristianos, el privilegio de especial protección de la Bailía a los antiguos mudéjares había dejado de tener efectividad. Ya no debería de haber diferencias de tribunales en función de una distinta religión de origen, porque esa situación ya no era legal, ya no era admitida; «viejos» o «nuevos», todos eran cristianos. Pero, de todos modos, tenemos algunas noticias de procesos de moriscos que interpusieron demandas ante este tribunal, huyendo de la jurisdicción de Abad. Así, una demanda de los pueblos del valle («la universitat de la vall de Alfandech») en 1538, protestando por un tema impositivo y su interpretación, en relación con un arrendamiento general de rentas señoriales («manament, murs y valls y dret de fulla»); el Bayle admitió a trámite el recurso y citó al convento ${ }^{17}$. En 1562, los pueblos del valle (las universidades del valle y Tavernes) interpusieron un «recors» ante el Bayle General contra la forma de realizar los cabreves; éste admitió algunas de sus peticiones (que se nombrase un «assessor assumpt» para entender de las quejas de los vasallos y para asesorar al Juez de Cabreves, así como que permaneciese en el valle donde estaban las propiedades), pero el convento rechazó la competencia de este tribunal, pues alegó que se trataba de una causa enfitéutica y solo al señor directo correspondía entender de ella ${ }^{18}$. Otra vez en 1564 , los vasallos (las universidades y singulares personas del valle de Alfandech) se quejaron ante el Bayle contra dos»cridas» del Abad, que limitaba su derecho a casarse, a otorgar escrituras ante el notario que

14. MEYERSON, M.: Op. cit., p. 363.

15. A veces, funcionarios de la Justicia del valle se negaron a entregar al Bayle a un musulmán de la morería de Xátiva; o llegaron a juzgar sumariamente y ahorcar a dos musulmanes vagabundos, que había cometido un robo en Xátiva, cuando estaba pendiente de resolución una apelación al Bayle (Ibídem: p. 363).

16. El convento y los vasallos del valle solicitan al Bayle General licencia para poder cargarse hasta 30.000 sueldos de propiedad en censales para abastecerse de trigo y carne, dada la sequía existente (ARV, Cl., c. 2.218-19, año 1529, ¿21, mensis Mady?). Existe otra petición semejante ante el Gobernador, esta vez solo por los vasallos (ARV: Cl., c. 1.922-23, año 1530).

17. Hay información sobre este pleito en ARV: Cl, c. 2.016-17, 2.212-13 y 2.217. No nos consta el resultado o su sentencia final.

18. Proceso iniciado el 17 de octubre de 1562, ARV: Cl, c. 2.044-45-46. Sin sentencia. 
ellos quisieran, así como por haber encarcelado a alguno de sus líderes ${ }^{19}$. En fin, en 1573 este tribunal admitió a trámite y falló una demanda autorizando a los vasallos de la Valldigna a cancelar un censal y renovarlo por otro ${ }^{20}$.

A nivel individual, en 1558 se abrió un proceso por apropiación indebida de varias joyas muy valiosas contra Ali Flori, de Tavernes, siendo incluso sometido a «turment»; presentó recurso ante el Bayle General, pero poco después renunció al «recors»» ${ }^{21}$. Por su parte, Luis Anton Amitti, morisco de Tavernes de Valldigna, fue encarcelado en 1569 por la Justicia del valle y embargados varios de sus bienes en distintas causas; entendiendo ser víctima de una situación abusiva, recurrió primeramente ante el Bayle General de Valencia en busca de protección, el cual admitió la causa y emplazó a las partes ante sí, con protesta del convento por incompetencia de jurisdicción ${ }^{22}$.

Desconocemos con precisión la actitud de la Bailía, pero nos consta que la demanda de 1538 y la de Perez Amitti fueron avocadas por la Real Audiencia, y el «recors» sobre cabreves de 1562 vino a quedar en nada, seguramente al reconocerse la plena competencia del señor directo en temas enfitéuticos (a través del Juez de Cabreves). En cambio, se entró en materia en la renovación de censales de 1573. Después de esta fecha, ya no tenemos noticia de escritos ante este tribunal, precisamente cuando se va haciendo más habitual recurrir ante la Real Audiencia huyendo de la justicia abacial.

Como se ve, persistió la tendencia a recurrir ante la Bailía, como una inercia heredada del pasado, cuando además no se habían borrado todavía las raíces mudéjares, las identidades moriscas. Pero incluso, en las demandas colectivas de la Valldigna, pleitean juntos pueblos de moriscos y pueblos de cristianos; obviamente aquellos son una aplastante mayoría, pero no se excluye, por ejemplo, la cristiana Xara, o a Simat, de población mixta.

Sin embargo, convendrá poner las cosas en su sitio: los casos, individuales o colectivos, de recurso o apelación ante la Bailía son escasos, muy pocos entre la masa de asuntos que se sustancian en le valle, o de los que pretenden burlar la Justicia local del Abad y acudir a los tribunales reales.

Es decir, por estas fuentes directas como por otras indirectas, cabe pensar que la Bailía dejó de ser un tribunal alternativo para los vasallos de Valldigna. El antiguo privilegio bajomedieval de protección de las minorías religiosas quedó vacío de conte-

19. Escrito de 10 de julio de 1564, ARV: Cl, c. 1.979. Sin sentencia.

20. El monasterio y las universidades del valle y particulares deben al magnifico Llorens Ortis, ciutadá, de Valencia, dos censales, uno de $1.533 \mathrm{~s} 4$ d de pensión y otro de $133 \mathrm{~s}$ (con un interés de 16 dineros por libra).Por este motivo les hacen «execuciones» y las universidades han decidido cancelarlo y renovarlo por otro de menor interés, vg. de 15 dineros por libra, pero el convento no les da licencia. Solicitan al Bayle autorización para suscribir un censal de hasta 25.000 sueldos, a $15 \mathrm{~d}$. por libra, lo que se les concede (proceso iniciado el 5 de febrero de 1573, ARV: Cl, c. 1.917-18, en mal estado).

21. Proceso iniciado el 6 de diciembre de 1558; acabó en sentencia absolutoria de 24 de abril de 1559 por falta de pruebas (ARV: Cl, c. 2.054-55). Podemos preguntarnos si la renuncia al recurso ante el Bayle fue resultado de una transacción, y/o del conocimiento de una sentencia absolutoria de la Justicia local.

22. Diversa información sobre los pleitos de este morisco en ARV: Cl, c. 2.114-15, 2.016-17; y ARV: Real Audiencia, procesos, $2^{\mathrm{a}}, \mathrm{S}, \mathrm{n}^{\mathrm{o}} 262$, escrito de 17 de septiembre de 1569. 
nido y ello se materializó progresivamente ${ }^{23}$. Moriscos y cristianos intentan superar la desconfianza y limitaciones que les merece la justicia señorial, la «Justicia del Abad», y buscar la protección (por la vía del conocimiento de las causas) de otros tribunales reales. En ese sentido, la Gobernación se mostrará pronto como un tribunal más solicitado, pero ambiguo y de competencias numerosas, además de poco definidas. Por vía de avocación, o por interposición directa de las demandas desde un principio, la Real Audiencia será progresivamente la vía judicial para huir y enfrentarse a la jurisdicción señorial. Diversos motivos jurisprudenciales o legales («suprema opresión», las causas consistoriales, los delitos nuevos como el bandolerismo) sirvieron de coartada para burlar la jurisdicción baronal ${ }^{24}$.

Al margen de estas dos cuestiones, con raíces en las estructuras políticas y jurídicas bajomedievales, los moriscos se incorporan de forma normal, ordinaria y habitual a la práctica procesal de la cort de Valldigna desde los años veinte y treinta del siglo XVI. En la documentación judicial, tanto en los libros de Justicia como en los distintos procesos civiles o penales, encontramos una igualdad de trato y actitud entre cristianos y moriscos. Los litigantes, en sus diversas modalidades (demandantes, demandados, testigos, imputados, procesados....), se identifican ante la Justicia, y en ello, además de otros rasgos (nombre completo, edad, origen, condición familiar...), el escribano hace constar en su caso, si los comparecientes son «cristians nous», como nota diferenciadora y particular. Pero fuera de esta matización, nada cambia a lo largo del proceso. En ese sentido, dicha precisión de raíz religiosa, nada afectaba ni iba a influir en el proceso o en el acto procesal (vg, una «declaratio de testimonis»), y podemos pensar en su inutilidad. Sin embargo, sin duda habrá que entenderla e interpretarla en el sentido de que, pese a la proximidad y similitudes de la vida cotidiana, a la identidad de algunos intereses y condiciones..., nunca se perdió o se olvidó definitivamente, en el ámbito territorial de la Valldigna, la disparidad de origen religioso, la diferencia entre los que eran cristianos viejos y los nuevos cristianos.

En esa tesitura, hay que anotar que la lengua materna hablada por los moriscos, la «algaravia», no fue un obstáculo. O al menos no insalvable, o de difícil superación. En principio, dado el carácter predominantemente oral e inmediato de la práctica judicial, era necesario conocer la lengua de la administración de Justicia y de sus principales gestores, que sin duda era el valenciano o «algemia». No dominarla suponía una limitación, una indefensión. Mal se podía comparecer directamente e interponer cualquier demanda o petición sin el dominio de aquella, ni responder a interrogatorios o preguntas diversas. De ahí que, quien no la dominase, tuviese la necesidad de buscar ayudas o colaboraciones puntuales. Así, según su propia afirmación, el cristiano residente en

23. Esa parece ser la razón de los recursos ante el Bayle General, aunque hay que precisar que no hemos visto citado expresamente en los documentos estudiados ese especial privilegio de la minorías religiosas

24. Para la contextualización y completa comprensión de estas afirmaciones, nos remitimos a la obra citada La Justicia del Abad (en prensa), en particular el capítulo I. No es fácil conocer con seguridad la postura doctrinal que tomaron los distintos tribunales, o cómo acabaron definitivamente algunos procesos, por el carácter fragmentario de éstos y por la ausencia generalizada de sentencias finales. 
Tavernes Joan Barreda tiene que acudir en 1603 a la «cort» a petición de su criado Miguel Redonet, "perque no sap parlar en algemia» y le había suplicado «que anas a parlar per ell a la cort p. que feya demanda a Visent Blanco de la dot de sa germana». Cuando Miguel Galip fue acusado con otros en 1585 por falso testimonio en un juicio civil, su defensa alegará en su descargo que es hombre de «bon juhi», querido por sus vecinos, fue buen jurado, y «que no tenia falta ninguna sino que sab poca algemia»; aún así, Galip no necesitó intérprete o traductor para declarar ante la Justicia. Pero no siempre fue así: de Miquel Cacherel, morisco de la Hombría, de 28 años, se dice en 1606, que «no sap tornar la algemia, que la enten un poch y no la sab tornar ques que no sap parlar en algemia»y, obviamente necesitó la ayuda de un intérprete.

Pero, en general, el carácter mixto del poblamiento en la Valldigna y la elevada proximidad de la vida cotidiana entre las dos poblaciones, hizo que una gran mayoría de la población adulta masculina, de origen morisco, entendiera la «algemia» o valenciano y se pudiera expresar en ella, con mayor o menor corrección, en un elevado nivel de bilingüismo ${ }^{25}$. Así, el 97’4\% de los moriscos varones adultos que declararon ante la Justicia de 1560 a 1609 lo hicieron directamente, sin necesidad de traductor. Dado que del 80 al 90\% de los demandantes, testigos, procesados......y litigantes en general, eran varones (y entre ellos, sobre todo los adultos), ello ya suponía una gran facilidad en la práctica judicial ${ }^{26}$. Es decir, la gran mayoría de la población morisca usuaria de la Justicia podía defenderse oralmente ante ella, sin necesidad general de terceros o de interpretes. El problema se podía plantear en el colectivo de mujeres adultas y en el de jóvenes. En el primero, un 58'4\%. de las comparecientes necesitaron traductor, sobre todo las procedentes de pueblos de exclusivo poblamiento morisco (Tavernes, Benifairó, Hombría...), pero no las residentes en Simat, lugar de poblamiento mixto. Pero la presencia de mujeres es escasa en la práctica judicial: nunca o casi nunca presentan demandas civiles o denuncias en su nombre, sino que lo hacen los varones de la familia. Su participación tiene más virtualidad en la práctica de la prueba testifical en causas penales, y aún así, no muchas veces. Algo parecido ocurre con el colectivo más heterogéneo de los jóvenes moriscos de ambos sexos (aunque la mayoría son varones) menores de veinte años, aún poco «socializados», de los que un 42\% $\%$ necesitaron intérprete. Sin embargo, su presencia procesal no es muy abundante, salvo en los muchos altercados y peleas que los «fadrins» (jóvenes no casados), a veces agrupa-

25. Nos hemos ocupado con detalle de estos temas en Ciscar PALlarés, E.: «Algaravía y Algemía. Precisiones sobre la lengua de los moriscos en el Reino de Valencia», Al-Qantara. Revista de Estudios Arabes, Madrid, 1994, vol. XV, pp. 131-162. A esta obra remitimos las citas documentales y ulteriores detalles, que ahora se analizan desde la perspectiva de la práctica judicial. Aludió a este tema en Valldigna, además de un enfoque global, BARCELó TORRES, C.: Minorías Islámicas en el País Valenciano. Historia y Dialecto, Valencia: Universidad de Valencia, 1984, pp. 141-142. Con carácter general, vid. VINCENT, B.:»Reflexión documentada sobre el uso del árabe y de las lenguas románicas en la España de los moriscos (ss. XVI-XVII)», Sharq Al-Andalus. Estudios árabes, Anales de la Universidad de Alicante, Alicante, 1993-1994, n 10-11, pp.731-748.

26. Evaluación aproximada de la práctica procesal, que traduce fiablemente la realidad, aunque no hemos procedido aún a una cuantificación sistemática. 
dos en «bandos» o facciones, organizan en las fiestas, reuniones, días festivos, paseos nocturnos, etc..

Para suplir las deficiencias de comunicación, en muy contadas ocasiones en la reiterada práctica procesal, se recurrió a un servicio de traducción o interpretación. Esta función no la podían desempeñar los notarios-escribanos, pues eran cristianos viejos ajenos a la Valldigna, desconocedores de la «algaravia». En consecuencia, una serie de personas residentes en el valle, que dominaban las dos lenguas, fueron requeridas puntualmente por la Justicia para hacer de intérpretes o traductores. Hemos contabilizado 43 personas diferentes, de los que 32 eran moriscos, pero otros 11 son cristianos de la Valldigna. No es un oficio o cargo habitual, sino puntual y circunstancial, aunque algunos de ellos lo ejercieron en bastantes ocasiones y suelen coincidir con personas bastante vinculadas con la actividad de la Justicia. Así, «missatges» como el cristiano Anton Hernández (1590, 1591, 1593), o los moriscos Alexandre Bolaix (1591 y 1594) o Geroni Aquem (1591); lugartenientes de Justicia, como Pere Marin o Pere Zenequi; Damiá Ripoll, el más usual de los procuradores del valle, que actuó como traductor en 1593, 1599 y 1607; un buen conocedor del árabe, Cosme Cruañes, cristiano de Simat, «persona experta e intelligent en lengua araviga», hermano del influyente Pere Cruañes, lugarteniente de Justicia de Tavernes durante muchos años, etc. Otros, su participación parece más ocasional, como Pere Meri, del que se dice que es «laurador resident en la casa del pare rector de Benifairó», o cuando unos padres traducen las declaraciones de sus hijos, menores de edad. En los procesos los traductores son identificados y juran su cargo antes de desempeñarlo. Normalmente no coinciden con los oficiales habilitados en un mismo proceso, sin duda para salvaguardar su independencia o imparcialidad, pero a veces por razones de facilidad o de economía procesal hace de intérprete el mismo «missatge» o «ministre» habitual de la corte, como los citados A. Hernández, A. Bolaix o G. Aquem.

De esta manera, quedaban subsanadas todas las dificultades que normalmente pudiera plantear el bilingüismo en la práctica judicial. Pero siempre cabía la excepción, el asunto particularmente embrollado, el «caso raro»....La traducción precisa de una lengua a otra, y con los matices adecuados, podía suscitar en ocasiones algún problema. En ese sentido llama la atención el proceso entre la viuda Maria Sayfona y su cuñado Hieroni Bannat, ambos moriscos de Benifairó (1591). Tras un pleito civil entre parientes por una partición de herencia, la primera acusó al segundo de haber dicho en público de ella que decía «falsos testimonios» en juicio. H. Bannat admitió que había dicho en algarabia «xehet adzar», pero que no significaba tal cosa sino que «vos parleu del que no sabeu», o que «vos dieu lo que no sabeu», no teniendo por tanto intención de calumniarla (aunque en el texto se dice injuriar). Los testigos respectivos de cada parte defienden las correspondientes posturas y ponen de relieve una amplia red de clientelismo, lo que se evidencia en la tacha de aquellos. De un joven de dieciséis o diecisiete años (Joan Ayronet) se dirá que es «bosal tonto molt poch intelligent e molt ignorant axi de paraules de algemia com de algaravia». Nadie declara con ayuda de intérprete y como el tema sobre si había habido delito o no dependía de la interpretación y traducción fidedigna que se diese a la citada expresión, llama la atención uno de 
los testigos, Gabriel Ximeno, cristiano viejo de Tavernes, cuarenta y tres años de edad, «que sab molt be algaravia» (y había actuado como intérprete en alguna ocasión); pero éste, un tanto confundido, no acaba de decidirse por ninguna de las dos versiones. Tras una larga batería de alegaciones y recursos por ambas partes, la Justicia acabará absolviendo a H. Bannat por la duda creada en el expediente y por un tecnicismo legal (en atención a un fuero del rey Martín, Bannat dijo esas palabras «no per veritat queu sabes sino per colera...») ${ }^{27}$. Sin embargo, este caso, cuya dificultad de base radica en un problema de interpretación o traducción filológica fidedigna, es excepcional en la práctica procesal valldignense.

En el ámbito escrito del árabe o algarabia, los problemas suscitados son casi imperceptibles. El alto nivel de analfabetismo de la época hacía que el recurso a la escritura fuese muy limitado, y en el caso de los moriscos, aún mayor por la presión social y religiosa sobre el islamismo en general. De hecho, en Valldigna solo una minoría de moriscos (el 11'6\%) firman en los procesos, especialmente los penales; son individuos de un cierto status económico, sobre todo comerciantes y agricultores acomodados, con algún nivel cultural y acostumbrados a llevar su contabilidad o cuentas de negocios en árabe. De 36 moriscos tabulados e individualizados de 1580 a 1609, que firman ante el escribano, 33 lo hacen en árabe, dos en romance y uno indistintamente. Y todos han declarado ante la Justicia en valenciano, sin necesidad de intérprete, por lo que esta particularidad no suscitó ningún problema ${ }^{28}$.

Dentro de la masa procesal conservada, son muy contadas las anotaciones o documentos en árabe, normalmente con escaso interés general (albaranes, recibos, donaciones..., de índole particular). Como caso excepcional, puede recordarse el proceso de falsedad documental y estafa suscitado en 1596. Miguel Alil, morisco de Tavernes, debía dinero a Miguel Bolluix, pero para evitar su responsabilidad presentó un albarán falso en algarabía, en que expresaba todo lo contrario, haciéndolo valer en su beneficio en un proceso civil. El tema trascendió y se abrió a instancias del fiscal un proceso penal por estafa, en el que otros cinco agricultores moriscos de la misma localidad, actuando como peritos conocedores del árabe, leyeron el albarán y lo tradujeron. M. Alil, que no sabía escribir, afirmó en un principio que lo redactó Luis Signell, «clavari» de Tavernes, tal como consta en el documento (aunque los testigos niegan que sea la letra de Signell). Otro testigo, Joan Cunyat Macastre, de Tavernes, admite que previamente Alil le propuso a él falsificar un albarán con el mismo objetivo, pero se negó a

27. Este complejo y largo proceso se encuentra en ARV: Clero, caja n. ${ }^{\circ}$ 2.224-25, aunque la sentencia se ubica en caja $\mathrm{n}^{\mathrm{o}} 2.132-34$.

28. Nos hemos ocupado del analfabetismo, con referencia a la Valldigna, en nuestro artículo «Cruz o Firma en la práctica procesal (Contribución a la medición de la alfabetización en el Reino de Valencia, siglos XVI-XVIII)», Estudis, Revista de Historia Moderna, Valencia, 1998, n 24, pp. 37-62, en particular pp. 54-55. Sobre el contexto educativo en árabe, vid. CísCAR PALLARÉs, E.: Vida Diaria y Mentalidades en el Campo Valenciano (La Valldigna, siglos XVI-XVIII), Valencia: Del Senia al Segura, 2002, pp. 202-211. 
ello. Finalmente, el acusado acaba por reconocer que lo falsificó Gorrinet, «lo barber de Alazquer», con algún testigo presencial de Favara ${ }^{29}$.

No solo eran tratados en igualdad de condiciones cristianos y moriscos ante la Justicia, sino que además estos últimos colaboraron en la práctica de la misma como oficiales. Desde luego, no como Justicias Mayores del valle, la máxima dignidad judicial, persona de gran confianza del Abad, pariente o conocido suyo, o a fines de siglo algún «frare llech». Tampoco obviamente como asesores (y redactores de sentencias), escribanos, abogados fiscales..., tanto por su nivel técnico como por ser desempeñados sobre todo por individuos ajenos a la Valldigna. Pero sí ocuparon los puestos que normalmente podían ejercer, y de hecho ocuparon, los vasallos del señorío. Así, el importante cargo de lugarteniente de Justicia, suplente y adjunto del Justicia Mayor, tanto a nivel local como, circunstancialmente, de manera general a todo el valle, y por tanto, con autoridad y potestad ejecutiva. De forma más instrumental, hubo muchos moriscos que ejercieron de «misatges» o «ministres» y de guardas rurales. Fenómeno que es usual y habitual a lo largo del siglo XVI, desde 1525-1526 y de forma progresivamente incrementada, pero quizá no anteriormente ${ }^{30}$.

Así, señalando solo algunos ejemplos ${ }^{31}$, fueron moriscos los lugartenientes de Justicia de Simat Franses Baya (1526, Foya Alta), Joan Giber (1530), aunque en esta localidad y la vecina Xara predominan ampliamente los lugartenientes cristianos. En Benifairó, los moriscos Joan Capulla (1560), Frances Boquerbi (1565), Lois Menig (1582), Geronimo Bannat (1592), Miguel Boquerbi (1604) Miguel Dido (1608) o Franses Baya (1609). En Fulell, o Alfullell, Llopo (1592). En Tavernes, Joan Plata (1560), Miguel Meymi (1562), Miguel Mereni (1564, 1578, 1582, 1588), Hieroni Silimilla (1572), Joan Corella (1575), Luis Signell (1575, 1576, 1577, 1578), Luis Rodova (1600), Agosti Castilli (1604), Luis ¿Redona? (1608) o Miguel Cortovi (1609). En la Hombria, Gaspar Ramonet (1562), Juan Faxar (1575), Miguel Gotit (1586), Joan Bonin (1591), Miguel Carimdi (1591) y Miguel Cortovi (1600, 1602). En Masalali, Miguel Zenequi (1589), o en Alcudiola, Luys Gaybell (1605).

No obstante, en los listados reconstruidos a partir de los procesos penales y Libros de Justicia, suelen primar los nombres cristianos sobre los de moriscos, aunque aquellos eran una minoría en la Valldigna (en torno a 15\% de la población). Así, por ejemplo, oriundos de Simat y Xara son los cristianos Jaume Pallás (1557), Miguel Salvany (1559), Pere Ribera (1560), Joan de la Fuente (1567), Joan Baptiste Almiñana (1572),

29. Proceso iniciado el 21 de junio de 1596, el Procurador Fiscal contra Miguel Alil, major de Tavernes (c. 2.135-36, con un duplicado en c. 2.210-11).

30. Sin haber sido objeto de estudio detenido por nuestra parte, no hemos encontrado referencias a cargos judiciales (lugartenientes, «misatges», guardas) mudéjares en los pocos procesos penales individuales anteriores a la conversión (en general, con mala conservación), pero sí otros cargos (jurados, alamín, alfaquí...). De igual forma, en el Libre Judiciari de 1515-1516 (c. 1.949-1.950).

31. Los nombres y cargos de lugartenientes, «misatges» y guardas rurales se han obtenido de diversa documentación (sobre todo procesos penales, además de libros de Justicia) del fondo de Valldigna en ARV: sección Clero (vid. el libro citado en nota 1). 
Joan Sala (1573, 1578, 1589...), Joan Hieroni Oliver (1575), Juan Selfa (1576), Franses Plana (1582), Miguel Geroni Ripoll (1584, 1592-93,1594, 1596, 1597), Joan Geroni Spi (1585), Joan Fons $(1588,1589,1591)$, Pere Selfa (1601, 1602, 1603), Pere Pelegri (1609), etc.

De igual manera, algunos cristianos desempeñaron el cargo de lugarteniente de Justicia en lugares de moriscos, como el cristiano Pere Marin, lugarteniente de Benifairó de Valldigna (1593, 1599); quizá era cristiano Pere Garcia, lugarteniente de Tavernes en 1599 y 1600, pero sobre todo el cristiano oriundo de Simat, Pere Cruanyes, hombre de confianza del convento, implicado en algunos asuntos de corrupción, que desempeñó su cargo en la morisca Tavernes, prácticamente casi toda su vida, siendo mencionado por primera vez en 1568 (manifestando que reside en el hostal) hasta los primeros años noventa ${ }^{32}$.

En lo concerniente a los «misatges» o «ministres», los cristianos con mucha frecuencia suelen ser apellidos extraños al valle, como Miguel Ximenez (Tavernes, 1596); Cosme Sarmiento (Simat 1575); Joan Gutierres (1576) Joan López, (1572-73, Foya Alta); Domingo Hernández (Simat, 1586, 1588), Diego Medina (1599), Cristofol Molina (1607), Mathia Trillo (1596), Sebastián Campos.... En cambio, los»misatges» moriscos, muy numerosos pero inferiores al porcentaje de población que representan en el señorío, son o suelen ser de linajes conocidos y originarios del valle. Así, en Tavernes, Hierony Calaf (1576), Geroni Aquem $(1585,1591,1592)$, Joan Alexandre Bolaix (1588, 1593, 1594, 1596), Geroni Teten (1591), Pere Sarset (1608), Joan Sarset (1597, 1598, 1599, 1600, 1603, 1604, 1606, 1608, probablemente en Tavernes). También hay cristianos que ejercen en localidades moriscas (vg. Miguel Ximenez, ministre de Tavernes en 1560).

En cuanto a los guardas rurales, varios apellidos son idénticos al de los «ministres», pero otros no. Así, ejercieron los dos cargos, en momentos diferentes o simultáneamente, el morisco Joan Sarset, o los cristianos Joan Belluga (1571) y Joan Belluga, menor (1597, 1606). Guardas moriscos fueron Miguel Aig (Tavernes, 1586, 1578, 1599), Miguel Muge («guardia de la vall», 1589), Joan Sarset (Tavernes, 1590, 1596). Antoni Texeda (Tavernes, 1604), Miguel Naxe (1607), quizá morisco era Antoni Senyat (Tavernes, 1607, 1608), entre otros cristianos (Frances Guillem, Tavernes, 1567; Pere Cuevas, «guarda de les vinyes de la senyoria», 1585; Miguel Vaquer, Simat, 1597), etc.

Por tanto, el mundo morisco, mayoritario en el valle, se incorporó de forma natural y ordinaria a la práctica y al funcionamiento de la administración de Justicia, con normalidad y en situación de igualdad de trato e identidad con los cristianos. La cort recibía las demandas civiles, las denuncias o querellas penales de los «cristians nous», como las de los cristianos, sin que hayamos observado diferencias en este sentido. La lengua peculiar de los moriscos no supuso un problema, tanto por el elevado nivel de

32. Pere Cruanyes es citado como lugarteniente de Justicia de Tavernes hasta 1594. De 1596 conocemos un proceso penal, por el que su viuda, Catherina Fons y de Cruanyes, residente en Simat, denuncia a Angela Signell (morisca de Tavernes) por doble venta de un campo, que compró y pagó Pere Cruanyes en 1592 (proceso de 21 de junio de 1596, ARV: Cl., c. 2186-87). 
bilingüismo entre los varones adultos y en menor grado entre mujeres y jóvenes. Un asiduo y ágil sistema de interpretación resolvía las incertidumbres que pudieran plantearse, sobre todo en las declaraciones testificales o directas, sin perjuicio de otros incidentes escasos (traducción de documentos en árabe...). Esa integración se consolidó ocupando puestos de oficiales, como lugartenientes de Justicia, «ministres» y guardias rurales, los cargos que habitualmente eran ocupados por los vasallos de señorío.

Sí que es verdad que la proporción de la participación morisca en el desempeño de oficios judiciales fue menor al porcentaje poblacional general, que hubo cristianos desempeñando esos puestos en lugares de moriscos, que quizá los cristianos merecían más confianza por parte del monasterio, que también es cierto que en las declaraciones ante la Justicia se hacía constar, en su caso, que el compareciente era «cristia nou», lo que era en principio (o normalmente) irrelevante para la tramitación de un proceso por cualquier delito o reclamación civil. Pese a elevados niveles de confraternidad, de convivencia y conocimiento mutuo entre cristianos y moriscos en el valle, nunca desapareció la conciencia de la propia identidad, de la diferencia profunda entre unos y otros, que en último lugar remitía a cuestiones religiosas practicadas ocultamente y a consecuencias culturales derivadas de aquellas; incluso, a mayor abundamiento, ante las posibles dudas de la fidelidad morisca en relación a la presencia esporádica, pero cercana, de piratas berberiscos o del peligro turco en general. La convivencia y la comunicación no quebraron nunca la conciencia de la desigualdad y de la jerarquía entre las dos comunidades ${ }^{33}$.

Pero, contando con todo ello, los moriscos se integraron bien, con normalidad en el ámbito judicial, el nivel de proximidad fue muy alto y el trato recibido fue, en general, el común al de los cristianos. La impresión resultante es de una mayor integración que en otros ámbitos diversos (religiosos, ciertas prácticas de vida cotidiana, seguridad frente a invasiones marítimas de corsarios...).

33. Nos hemos ocupado de este tema en La Valldigna, siglos XVI y XVII. Cambio y continuidad en el campo valenciano, Valencia: Diputación de Valencia, 1997, en particular el epígrafe «Moriscos y cristianos: una diversidad limitada y una convivencia con matices» (pp. 155-159). 